\title{
A ANCESTRALIDADE NA POÉTICA DE FAUSTO ANTONIO E A VIRADA SINTÁTICA DA LINGUAGEM: ALGUMAS INTERPRETAÇÕES A PARTIR DE BACHELARD
}

The ancestrality in the Fausto Antonio's poetics and the syntactic virade of the language: some interpretations from Bachelard RONALD OLIVEIRA ${ }^{1}$

RESUMO: Este texto consiste em um estudo inicial sobre a poética de Fausto Antonio. A exposição dar-se-á a partir da interpretação da obra Poética do Devaneio de Gaston Bachelard. A proposta é de empreender a análise das profundidades das imagens impressas na escrita do nosso poeta. Nesse sentido, os espaços localizados entre a superfície e a profundidade de um texto sendo desvelados anunciam uma nova sintaxe a qual empregamos o termo: virada; que se traduz como uma inversão por meio da contradição. E o todo ontológico-poético se acomoda na ancestralidade destes espaços contraditórios. Esperamos a partir deste texto apresentar nossa proposta com o objetivo de melhor esclarecê-la ao longo da possibilidade de futuras publicações. Palavras-chave: Fausto Antonio; Bachelard; imagens.

RÉSUMÉ: Ce texte se compose d'une première étude sur la poétique de Fausto Antonio. L'exposition donnera de l'interprétation de œuvre La Poétique de la Reverie de Gaston Bachelard. La proposition est de procéder à l'analyse de la profondeur des images imprimées dans l'écriture de notre poète. En ce sens, les espaces situés entre la surface et la profondeur étant dévoilé annonçant une nouvelle syntaxe qui utilisent le terme: tounant; qui se traduit par une inversion au moyen de la contradiction. Et le tout ontologique poétique qui installe les ancêtres de ces espaces contradictoires. Nous attendons de ce texte à présenter notre proposition afin de mieux clarifier sur la possibilité de futures publications.

Mots-clés: Fausto Antonio; Bachelard; images.

\section{CONSIDERAÇÕES INICIAIS}

\footnotetext{
${ }^{1}$ Graduado em Ciências Humanas pela UNILAB.
} 
Quantas experiências

de metafísica concreta não teríamos se prestássemos mais atenção ao devaneio poético!

Gaston Bachelard - A poética do Devaneio

O presente trabalho investiga o nascimento de uma concepção de poética aliada aos temas africanos-ancestrais no espaço da escrita de Fausto Antonio; Poeta, romancista, dramaturgo e professor universitário. Fausto Antonio neste ano corrente completa trinta anos de ativa publicação. Dentre sua poesia e prosa podemos enumerar o romance Exumos e a sua enigmática poesia Vaníssima Senhora. Além da peça teatral: De que valem os portões o escritor em questão adentra agora o universo infantil com suas Memórias do Carvoeiro.

Conheci o professor Fausto Antonio nos espaços da Universidade Internacional da Integração da Lusofonia afrobrasileira (UNILAB) em meados de 2013 e logo me senti atraído pelas suas atitudes visivelmente artísticas. Um escritor e teórico preocupado com as questões da colonização africana em nosso tempo e com a língua e cultura portuguesa. Foi a partir do primeiro contato com as suas aulas que tive acesso aos seus livros. Entre vários diálogos começamos um processo de pesquisa (extra-formal). Uma análise de vida dos estudantes localizados neste espaço incluído a mim; e de facto, foi um verdadeiro mergulho na poesia.

Para traçarmos um artigo onde os espaços poéticos comportem a tradição negro-africana e ancestral é preciso ir mais longe. É preciso uma pretensão global. Ora, se esta pretensão nos põe à escuta do Ser, isto é, se este Ser é visto como uma extensão do social é preciso uma concepção do todo ontológico. Mas um todo não pode negar suas mínimas partes tampouco a relação entre estas. Assim um sistema cultural, estético, ético, religioso e filosófico não pode ser visto e analisado sem as suas contradições. Qual a maior contradição de um sistema de pensamentos e vivências?

Para responder esta questão vamos primeiramente ser sinceros a respeito da possibilidade de existência de um sistema. Aparentemente os objetos no mundo são delimitados e visíveis. No entanto, a pergunta subjacente aos objetos no mundo é exatamente o que faz de um objeto um objeto e de um mundo um mundo. Nesse sentido, não há como pressupor um globo epistemológico sem recortes. As des-territorializações e descolonizações da linguagem é vista como ancestral na medida que se impõe como retroalimentação contínua entre estrutura e ato. Primeiramente estamos a falar de duas grandes partes culturais do planeta: A África e a sua tradição negra-ancestral e as relações ancestrais entre o mundo como um todo. Portanto, temos 
aqui dois espaços que se entrecruzam, isto é, que se interpenetram. Daí que surge o nosso problema central: o que é ancestralidade? Existe algum "conceito" sem sujeito-objeto neste espaço? Afirmamos que não.

\section{A POÉTICA DO UMBIGO E DA PEDRA}

O Ocidente, com suas tradições eminentemente teóricas, tem retirado o homem de seu núcleo. As Teorias articulam conceitos que muitas vezes estão distantes de sua práxis. Acreditamos que a própria filosofia realizada no Ocidente não consiste em uma expressão da prática original, pois desloca o papel central da fala, da oralidade. Ora, se estamos a falar de atos de fala então não poderíamos partir de outro núcleo que não de uma poética que segue a dialética do Ser em seu dinamismo metafísico. Mas o Ser possui toda uma complexidade dialética: Macho - Fêmea. Dia - Noite. Ser- Não Ser. Portanto para seguirmos Bachelard de perto é preciso escutálo em sua profunda contradição:

Parece-nos que a estilística teria todo interesse em acrescentar aos seus diferentes métodos de exame uma pesquisa mais ou menos sistemática sobre a abundância relativa dos masculinos e femininos. Mas nesse domínio uma estatística não bastaria. Importa determinar "pesos", medir a tonalidade das preferências. Para nos prepararmos para essas medições sentimentais do vocabulário de um autor, talvez fosse necessário - fico totalmente confuso ao dar este conselho - concordar em tornar-se, nas doces horas de repouso, um sonhador de palavras. No entanto, se hesito quanto ao método, tenho mais confiança nos exemplos vividos pelos poetas. (BACHELARD, 2009, p. 37)

Indubitavelmente, a filosofia da ancestralidade em Bachelard é uma filosofia da subjetividade da contradição. Suas microestruturas sugerem-nos um mundo de possibilidades. E a linguagem por onde esses sistemas transitam é o complexo ontológico do ancestral. Dito de outro modo, o que chamamos de ancestral nada mais é que um emaranhado grande de teias dispersas e ao mesmo tempo conectadas por: Exú (nosso arquétipo oriundo da ancestralidade africana). Justamente neste ponto faz-se mister a desenvoltura de um aprofundamento na ancestralidade negro-africana. De uma ancestralidade onde a textura negra é a ponte para a poética da ancestralidade.

Dessa forma nosso trabalho assume a seguinte "forma": Em primeiro lugar estamos a falar de espaços poéticos. Em segundo, de uma epistemologia regional. Em terceiro, de uma ancestralidade afriobrasileira sem essencialismos, onde a oralidade é o núcleo da vida. Em quarto, das possibilidades de existência desta ancestralidade, isto é, da ancestralidade enquanto 
contradição ${ }^{1}$. O nosso objetivo primordial é: entender a ancestralidade. A partir disso delimitar os espaços localizados entre a ancestralidade.

Por isso, nosso diálogo será, segundo nossa visão, entre dois grandes articuladores da ancestralidade: Gaston Bachelard (filosofia e poesia) - Fausto Antonio (Poesia e sociedade). Desta maneira, para nos inserirmos neste debate vamos propor um estudo aprofundado da prosa poética de Fausto e da obra de Bachelard: A Poética do Devaneio. Quando falamos em Ancestralidade estamos propondo uma visão de idioma mais abrangente, sob uma ótica da pluralidade da fala poética.

Apesar de toda essa pretensão estamos conscientes dos perigos das encruzilhadas da escrita. Reconhecemos as dificuldades de um projeto epistemológico nesse sentido e, portanto, esta defesa não se trata de um jogo aleatório. Antes disso se constitui em uma empreitada em busca da verdade. Por sua vez, o ser da verdade, provando ele mesmo uma exceção a todo e qualquer predicado de uma situação, ou seja, uma ocorrência de verdade desdobrada, por assim dizer, é um procedimento de natureza genérica.

Levando em consideração essa problemática, temos que descompor as estruturas da linguagem: não se trata de uma proposta irracional, mas de um deslocamento para a esfera poética, isto é, para a esfera mais exata das delimitações. O problema é, pois, de ordem metafísica: o que caracteriza um ente da linguagem enquanto ente na multiplicidade? Isto exigiria de nós um esforço para além da filosofia.

Numa palavra, para falar em subjetividade da linguagem, pluralidade de uma língua e articulação da fala poética é preciso inegavelmente pensar nas inconsistências do pensamento enquanto pensado. Neste caso a lógica é vista como fruto de uma escolha não uma regra absoluta, ou seja, o grande problema da filosofia e da cultura é a diferença entre objetos e lógica. Em tom de ironia Bachelard diz: "Quantas pesquisas não seriam necessárias para distinguir entre o mau olhado contra os homens e o mau olhado contra as coisas!" (BACHELARD, 2009, p. 177).

Isto porque, para nós, a imaginação é uma propriedade da mente e por isso não faz parte da filosofia, mas é a contraparte dela. Entretanto, quais as propriedades dos objetos poéticos? Segundo nossa interpretação do raciocínio de Bachelard na Poética do Devaneio existem dois tipos de idiomas da linguagem: o idioma material que é o idioma da ciência e o idioma formal referido a gramática. Mas estes idiomas estão intimamente articulados de modo que um não existe sem o outro atuando ininterruptamente e igualmente em momentos diferentes. Neste caso, a vírgula é um objeto poético. 
Ora, neste caso, forma e matéria nos falam de outra linguagem para além do idioma. Não há nada de novo aqui: Heidegger, por exemplo, nos fala que a nossa linguagem formal é na verdade uma linguagem artificial. Pode-se afirmar, seguindo Heidegger, que a ordenação da forma implica em uma situação paradoxal da linguagem justamente por que as sentenças de uma teoria científica são incapazes de serem articuladas no seio de suas diferenças. O que quer dizer que existem dois tipos de regras para uma semântica de um idioma formal ou para uma teoria formal das formas linguísticas. De modo que o domínio de uma metalinguagem só é possível após uma virada sintática, isto é, da saída para a negação da forma estrutural da linguagem para uma poética do imaginário. Complementando este raciocínio diz Fausto: O paraíso, o lugar palavra, desmoronaria e redundaria numa nova viagem. (ANTONIO, 2006, p.139).

Nesse sentido, a verdade plena é inacessível e indeterminada e desloca seu interior para a poesia: a continuidade do ser sonhador. Em última instância a poesia opera pela linguagem e a transforma em algo que a filosofia não consegue: o acaso. De determinação para indeterminação. Acontece que todo desdobramento linguístico se coloca no extremo de uma encruzilhada do sentido - entre bifurcações de bifurcações. Então todo procedimento sempre se chocará com a sua contradição, desequilíbrio e inconsistência. Por isso mesmo, Exú simboliza o nosso princípio de equilíbrio e é o controle da equivalência e do problema da indefinição dos meta-níveis das contradições do raciocínio.

Por sua vez, as suas semânticas atuam como ascensão da totalidade da vivência dos dados da realidade. Um exemplo claro disso são os protoidiomas das línguas bantu com suas exageradas substantivações e uso extensivo de prefixos. Esta é uma marca inequívoca de sua pluralidade de sistemas onde a sua contradição atua como anti-sistema gerando inclusive atonalidades. Não é nossa pretensão estudar essas nuances agora.

Inicialmente temos que compreender que a filosofia provoca uma mudança de postura. A passagem de uma postura que vai se perguntar sobre o conhecimento válido. Este caráter filosofal emerge em uma nova tarefa que irrompe na necessidade de um processo de negação, pois a negação é o contra-conceito que vincula um conceito. Aqui está a raiz dialética da cultura. Portanto, a filosofia do não há algum tempo predita por Bachelard nada mais é que uma confirmação da explicação do verdadeiro em suas possibilidades de existência nos complexos de cultura. Assim, a contradição é uma condição intransponível que se direciona para a negação em busca de conteúdos significativos novos num infinito alargamento do interior dos sonhos noturnos.

Para Fausto Antonio, o mundo é um conto mitologicamente fundado e a sua estrutura é estritamente transcendental, isto é, o seu fenomênico no sentido de Ser é epistemológico. E ele 
parece não saber onde começa e termina o poeta. A 'intencionalidade' da cultura em sua poesia se manifesta ao tentar analisar a vida como condição de volta da filosofia como coisa-para-mim. É a refutação do absoluto na cognoscibilidade do seu mundo. Por isso, os atos dos sujeitos em sua poesia são atos constitutivos de intencionalidade sem direcionalidade, ou seja, são atos em direção aos atos das coisas em si mesmas. E é justamente a maneira desse Ser que faz dessas vivências um enigma intencional. No romance Exumos o poeta diz:

Mas a impressão dos homens de um dia para o outro muda. O calendário invariavelmente marca, sempre, domingo de feira. Domingo de missa. Domingo é um dia e, sendo o primeiro, como o criador descansou no primeiro. Como o criador descansou no primeiro do mundo? O primeiro dia ele ficou pensando o mundo. Depois contou a alguém que ele existia. E tudo cresceu. Foi se avolumando. A terra e os homens são na verdade uma longa história contada. (ANTONIO, 2006, p.75,).

Seguindo Bachelad, poderíamos supor que a subjetividade dos idiomas é a fonte de uma nova reviravolta na linguagem. Ora, quando se fala de cultura de um mundo geral pressupõe se que esse dado já não é absoluto e que a sua instância está localizada onde ela mesma se revela. A cultura nesse sentido é uma filosofia do sentido: são paraísos artificiais: Os paraísos artificiais foram escritos para serem lidos, com a certeza de que o valor poético seria, do autor para o leitor, o meio de comunicação, (Cf. BACHELARD, p 2009, p. 164).

A dimensão de tradição negro-africana é colocada neste texto como pretensão de dar visibilidade às ambivalências próprias da ancestralidade desta tradição. Envolve, pois, uma dimensão de efetivação do conhecimento sem fugir das aporias de qualquer sistema assim e de um retorno ao idioma da vida em sua semântica e pragmática. Trata-se de clarificar que todo devaneio é uma maneira própria de imaginar o mundo para além de uma teoria de qualquer significado. Quer dizer, a linguagem não vive sem a sombra do influxo do Ser na complexidade social de seus atos. A ação própria do dinamismo da linguagem é o que chamamos de ancestralidade.

O recorte geográfico deste trabalho está precisamente entre suas ancestralidades e a partir dele propomos um projeto poético epistemológico. A virada proporcionada pela ancestralidade se trata de uma visão holística de sistemas complexos de conhecimento onde a poesia atua enquanto anti-estrutura da subjetividade da linguagem. Neste sentido todo sistema epistemológico possui a sua contraparte na oralidade. Em nosso caso específico: o da tradição ontológica ancestral iniciada por Bachelard. É esta tradição que habita os entremeios dos espaços poéticos. Para apoiar nossa tese seguimos o argumento da filósofa portuguesa Maria Luisa Porto Carrero: 
Ora, a vida ultrapassa a textura meramente estática da representação, é dinamismo que misteriosamente se transforma em projeto, mediante a irrupção de estruturas comunicativas e simbólicas que iniciam uma nova ordem na realidade: aquela que é marcada pelo aparecimento da ética, da linguagem, da justiça e da história, fenômenos que inauguram o reino do sentido, que alimenta o radical questionamento dos seres humanos e exigem partilha. (CARREIRO, 2007, p.181,).

Para nós o poético é aquilo que têm a capacidade de saltar da sua esfera oculta, individual para o universal. Isto não pode ocorrer sem as suas contradições de onde procede qualquer sistema. Ora, qual a contradição de um sistema? É exatamente aquilo que além de não ser sistema o rejeita e o subverte, isto é, a poesia neste sentido é transcendência. O objetivo é que ao eleger a poesia como chave hermenêutica para rejuntar saberes crie-se uma metalinguagem e que esta metalinguagem gere suporte para que outras disciplinas fragmentadas possam manter um diálogo constante entre o conceito de cultura e os estudos poético/filosóficos da ancestralidade.

Calcado na ontologia poética de Gaston Bachelard, este artigo propõe realizar uma análise da poética de Fausto em alguns de seus escritos. Desejamos investigar como a cosmovisão poética de Fausto se manifesta na Natureza ontológica como uma configuração do ser ancestral no homem contemporâneo.

A poética de Fausto é, portanto, o espaço eleito para as discussões sobre os modos como as diferentes expressões e arquétipos fenomenológicos da ancestralidade são recuperados. As metáforas do umbigo, da caverna, do oco, da pedra, entre outros significantes que delimitaremos ao longo da crítica tomam como base o método hermenêutico ontológico de análise. Os ritos entre objetos e palavras originam acidentes nas estruturas da linguagem poética e por sua vez em suas dimensões sintático-semânticas; Um ponto, uma vígula, um período, uma linha, são vistas em nossa proposta como obstáculos para o des-lizar do estatuto poético do Ser que transpassa os corpos e desejos profundos dos entes humanos.

Fausto Antonio sintetiza a força-motriz de sua criação poética: o corpo-a-corpo com a palavra e seus "ritos", energizados pela "paixão". Não, aquela que arrasta e escraviza o ser, mas a que se manifesta como tensão interna e continua que unifica as forças do eu e, ao mesmo tempo, o leva a fundir-se com o outro, não necessariamente o outro do ato amoroso, mas principalmente o outro latente no verdadeiro ato criador (de arte, de pensamento, de poesia...). (COELHO, 1996, p. 259).

Em seu artigo publicado pela revista Letras da PUCCAMP de 1996: A palavra em busca do absoluto inaugural do ser, Nelly Novaes Coelho, professora da USP e militante da crítica literária aponta a escrita de Fausto Antonio como uma arte criadora do que existe e do que ainda não existe, quem cria essa arte é um ser pensante e o pensar existe dentro de uma cotidianidade existencial. 
Esta poética por sua vez, mantém-se viva na medida em que este ser é afetado por meio de atos criadores e formadores de linguagem. A linguagem artística de Fausto Antonio perpassa a vida e a morte, estando elas contidas nas cavernas e grutas, no obscuro e no sagrado, no belo do húmus e na pedra oca que contém o vazio do nada. A ausência de tudo impulsiona a transcendência da linguagem por meio dela própria; é como na pintura cubista de Pablo Picasso, escultórica, multidimensional, percebendo-se diferentes planos e volumes, renunciando à perspectiva europeia, assumindo, portanto, a forma de uma prosa poética, romanesca, polifônica e híbrida. Diante dessa diversidade de modalidades de linguagens artísticas, como interpretar a poética de Fausto Antonio? Façamos novamente o uso das palavras de Nelly Novaes:

Poesia que se engendra na órbita do moderno (ou pós-moderno?) a de Fausto Antonio se constrói no embate das emoções, sensações, vivências de um eu com as palavras que devem torna-las concretas, existentes, comunicáveis ao outro. Como nos diz a Fenomenologia: "O que não foi nomeado, não existe". E é esse o drama do poeta contemporâneo: saber que a palavra é o único e irredutível caminho, para ele comunicar ao outro a sua invisível experiência de vida, sabendo, ao mesmo tempo, que a Palavra é sempre insuficiente nessa nomeação. Nesse sentido, a escrita de Fausto Antonio resulta numa agônica interrogação em "circuito fechado", parte da palavra, pelo qual o mundo existe, e volta a ela mesma: escrita consciente de que a transcendência foi vedada ao homem, ou melhor, que a palavra científica, ao negar a palavra revelada, destruiu o "centro sagrado" do mundo e não conseguiu substituí-lo por outro. Cabe ao poeta a tarefa de resgatá-lo. É esse desafio, há muito, lançado aos homens de nosso tempo. (COELHO, 1996, p.261).

A hipótese construída nesse texto é que a poética de Fausto é pré-determinada por uma preocupação em conceber uma formação cosmogônica e antropogônica do universo que, nascendo do des-velamento da imagem/palavra e retornando novamente a ela, expressa-se como possibilidade de renascimento do ser. Fausto nos diz em um trecho de sua bela poesia: Vaníssima Senhora:

Às vezes vidros, vidros e relógios de rosários. Ante a face refrangida O som dos cascos... $\mathrm{E}$ as mortes corrosivas nas gengivas.

Outras vezes, sem repouso, nas conchas de Deus, suas bocas de urina, cujos óvulos, consoantes sopros, transpassam num ovo inaugural: Umbigos adormecidos que, enleados sob as águas, arrastam pérolas, infensas pedras e delas me visto, E delas me alimento.(ANTONIO,2005). 
Em sua poética o umbigo é retratado como herói. Na mitologia ioruba, o umbigo é o local onde convergem nascimento e morte do ser, é por assim dizer uma encruzilhada, é Ilê Ifé- o umbigo do universo. Em comparação ao umbigo como local de origem do mundo encontramos na mitologia grega (e no pensamento órfico em particular), Phanes: o ser primordial alado e dourado que foi chocado de dentro do ovo cósmico brilhante que era a fonte do universo. Chamado de Protogonos (primogênito) e Eros (Amor) — sendo a semente dos deuses e dos homens_- Phanes significa "Manifestador" ou "Revelador," e se relaciona às palavras gregas "luz" e "resplandecer". Um antigo hino órfico dirige-se a ele desse modo: "Inefável, oculto, reluzente rebento, cujo movimento é um zumbido, dissipaste a névoa escura diante dos teus olhos e, batendo as asas, rodopiaste e trouxeste pura luz a este mundo".

Ainda mais importante, o ovo era tido como uma imagem do universo, o macrocosmo. Ao longo da narrativa, por meio da imagem do ovo, o "eu" lírico questiona o seu próprio lugar no mundo e expressa o transcendental e o sagrado que perpassam pela questão existencial da morte. Em certa altura do romance Exumos o escritor indaga:

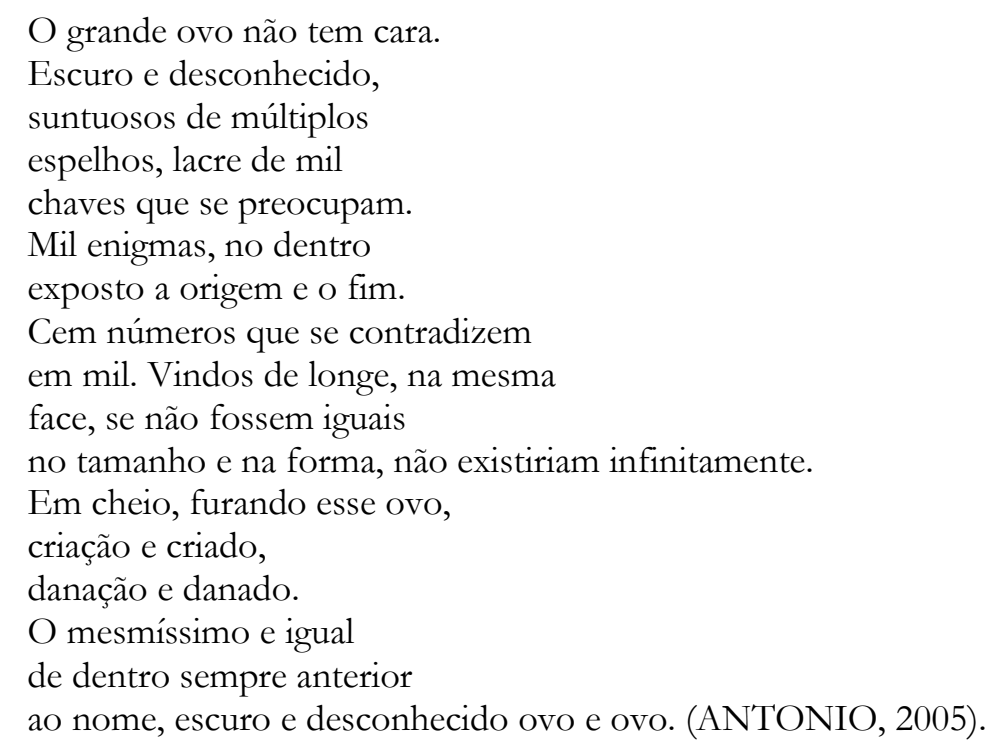

O ovo sendo espaço de abrigo e nascimento enclausura o ser em suas potências criadoras de atos. Atos estes noturnos, inequivocamente no inconsciente dos seus sonhos do poeta. A exemplo disso, em $A$ Poética do Devaneio, Bachelard faz referência ao tomo de alquimia Rosarium Philosophorum. Neste, verificamos imagens que representam a origem das coisas, o casal alquímico, a androgenia do ser primordial. Encontramos então uma interpretação cabível para a poesia de Fausto anteriormente citada. O filósofo afirma:

A androginidade do sonhador vai se projetar numa androginidade do mundo. Examinando em detalhe as doze imagens, juntando-lhes as dialéticas do Sol e da Lua, do fogo e da água, do dragão e da pomba, dos cabelos curtos e das madeixas, reconhece-se a potência dos devaneios associados, que são também 
postos sob o signo do adepto e de sua companheira. Aqui, igualam-se dois devaneios de cultura. (BACHELARD, 2009, p. 75)

O verbo que emerge do ser poético apresenta-se ontológica e socialmente ao mundo por meio de uma espécie de "metafísica existencialista", advinda da tradição negro-africana vivenciada pelo escritor, esboçando uma realidade viva, energética, existência permeada de sensualidade corpo a corpo, do erotismo das palavras e enquanto fenômeno derivado de um modelo capitalista de sociedade que sofre como conjunto excluído, destituído e marginalizado.

O espaço da narrativa nos romances Exumos, V anissima Senhora e Descalvado, é constituído por um ambiente que assume tonalidades muitas vezes sombrias. O escuro e os lugares sombrios são registros da ancestralidade, eles assumem um valor semiótico peculiar na escrita de Fausto. Para além da polifonia inserida na arte de Fausto, observamos também na estrutura profunda da hermenêutica e exegese textual questões relativas ao místico, ao poético associado ao divino que, co-habita entre nascimento e morte. Bachelard em A poética do Devaneio, diz:

O sonho noturno, ao contrário do devaneio, quase não conhece essa plasticidade macia. Seu espaço está atravancado de sólidos - e os sólidos sempre trazem de reserva uma hostilidade infalível. Têm as suas formas - e, quando uma forma aparece, é preciso pensar, é preciso nomear. No sonho noturno, o sonhador padece de uma geometria dura, é no sonho noturno que um objeto pontiagudo nos fere assim que o vemos. Nos pesadelos da noite, os objetos são maldosos. (BACHELARD, 2009, p. 162).

Desejamos entender este sonho do poeta; em compreender a criação: o devaneio do alquimista que observa o ovo. A arte então, para o escritor campinense, é resultado de uma compulsão à repetição do trinômio Exumos, Exu e Húmus, assim nos afirma, Eduardo Guimarães, professor do Instituto de Estudos da Linguagem da UNICAMP, na apresentação de Vinte anos de Prosa:

A obsessão como forma de construir. A reiteração sempre em outro lugar. A morte, a vida. O antes desta vida. A devoração como história (exumação) da vida: "E se comer (o umbigo) terei no prato: meu pai e minha mãe antes do nascimento". O líquido e o sólido: a placenta e a pedra. A relação dos corpos transformada em linguagem "Por isso o umbigo recebe muitas vezes o nome de: Eu te amo, eu gostei de você, eu odiei você". Exumos, Exu. Húmus. Exumar. Exumação. Este corpo com a vida e a morte, com o mundo, a técnica, o místico, a mídia é o móvel deste texto que vai do poético ao narrativo sem que se ponha a contar efetivamente uma história. Mas que se dá como a razão de tantas histórias. (GUIMARÃES, 1995, p. 20)

Atentemos ao que se manifesta no levantamento da estrutura profunda do texto de Fausto, como neste fragmento de sua poesia intitulada $O$ sexo das pedras:

Uma pedra comprida e pontiaguda 
Achou uma outra na altura certa

Para ferir, (até achar uma pedra),

Até achar a pedra certa, que nem fere,

Nem alisa. Mas faz mexer os quadris,

É uma pedra embaixo e duas pedrinhas,

Uma em cima, vale duas. Parece boca,

Mas é pedra. (ANTONIO, 2006).

O fragmento aponta para uma poética centralizada na dialética entre a metáfora da excitação erótica de uma pedra que, pode representar tanto a palavra/imagem enquanto linguagem artística, como a científica como lugar de tessitura do real. Consideramos esse o caminho para rompermos com os limites da linguagem e canal pelo qual poderemos adentrar em um diálogo interdisciplinar. Consequentemente a poesia é o lugar privilegiado para a construção de 'chaves' interpretativas com as quais trataremos de discussões calcadas em uma perspectiva poético-fenomenológica; na eroticidade advinda das sensações corpóreas e espirituais. Criando assim uma encruzilhada entre poesia, linguagem e filosofia.

Da obra Literatura e Afrodescendência no Brasil: Antologia crítica, organizada por Eduardo de Assis Duarte, professor aposentado e colaborador do Programa de Pós-graduação em Letras: Estudos Literários da UFMG. Nós fazemos valer a posição da crítica literária Maria Beatriz Bastos que afirma que o discurso de Fausto é permeado por uma tentativa de explicitar o conceito de identidade imerso no ser social/ancestral que, ao reforçar o debate acerca da alteridade, fortalece a proposta também do presente trabalho, a de apresentar uma ontologia social da textura negra a partir da hermenêutica da prosa de Fausto. Constatamos isso na seguinte afirmação da crítica:

Assim, em sua análise, Fausto investe contra o discurso que busca essencializar a identidade do afrodescendente, uma vez que, para ele, esta deve ser buscada no "trânsito-encruzilhada". A forma hifienizada é essencial, é preciso reconhecer a sobreposição e a fratura na identidade negra, caso contrário, alerta Fausto, será "incapaz de um movimento próprio, não pode participar de nenhum movimento contraditório, de nenhuma dialética". Subverte, assim, qualquer tentativa de fixação da identidade negra em um desenho homogêneo e concluso: “(...) ser negro é um processo. A negrura não pode, portanto, ser apreendida como uma essência e nem ser reduzida à cor da pele”. (BASTOS, 2011, p.296).

Este transito-encruzilhada a partir da ótica artística enquanto produção do ser social se apresenta por meio da convergência de múltiplas linguagens. Por conseguinte, confirmamos que a escrita de Fausto Antonio encontra-se em constante diálogo por meio do fenômeno da intertextualidade ou do processo de hibridismo, com as artes plásticas, dramáticas e audiovisuais, apoiada numa explosão imagética. Vejamos o que ora afirmamos nesse trecho em forma prosaica de Descalvado: 
A tela de um azul imenso e longamente pontilhado traz, no umbigo dilatado, o anjo atrás do homem e, atrás do anjo, o verbo divino. E o visionário lê, além dos sulcos e da vigorosa arquitetura, "é bem possível que faça dias e noites de fúrias e revoltadas pinceladas”. (ANTONIO, 2006, p. 152).

Constatamos nessa passagem que tanto a prosa como a poesia do escritor em questão, tendo como sustentáculo sintagmas tão pleonásticos como verdadeiros, origina intensas variações semânticas. Observemos o seguinte trecho da obra Vinte anos de prosa de Fausto:

O começo do oco é o oco do nada. Comerei então? Cada bocado uma pedra, sinto o gosto de pedras vulcanizadas, árvores petrificadas. Quero o húmus, a umidade no escuro deleita-me. Quero regozijar-me em ter água, o correr dela entre os dedos, sem poder bebe, alimenta-me. A razão dos meus dias é fadiga de tentar líquido uma gota. (ANTONIO, 2006, p.22).

Ao analisar a obra de Fausto Antonio a crítica já empreendida aponta exatamente para um embate entre a palavra/imagem produzida pela ciência e o verbo que emerge do ser poético que sonha. Bachelard afirma:

A correlação do sonhador ao seu mundo é uma correlação forte. É esse mundo vivido pelo devaneio que remete mais diretamente ao ser do homem solitário. O homem solitário possui diretamente os mundos por ele sonhados. Para duvidar dos mundos do devaneio, seria preciso não sonhar, seria preciso sair do devaneio. O homem do devaneio e o mundo do seu devaneio estão muito próximos, tocam-se, compenetram-se. Estão no mesmo plano de ser; se for necessário ligar o ser do homem ao ser do homem, o cogito do devaneio há de anunciar-se assim: eu sonho o mundo; logo, o mundo existe tal como eu sonho. (BACHELARD, 2009, p. 152).

Da escrita do romance Exumos que habita em um contexto de realidade angustiante, do cotidiano de zonas periféricas, Fausto elege o seu herói como o umbigo. O herói é o que recria a linguagem; isto é, é o ser da virada. Em certos trechos o "eu" de Fausto exprime um verdadeiro ato sincero:

Agora que estou com o meu herói posso viver tranquilamente. Mas é duro olhá-lo, é duro ir tendo do óbvio a sensação de proximidade. E ele foi crescendo e o seu ar estéril aprisionou-me a palavra. Depois que ele se tornou meu herói, eu estou com medo de tocá-lo e senti-lo com a vida, frágil. Mais ainda, um herói é um grande violador de silêncios, ele manipula a palavra com uma lança, e fere. Mesmo assim quero esclarecê-lo, e esclarecer os ritos, e desritualizar era o desejo de queimá-lo? Rastreá-lo com palavras?, mesmo as inúteis? Eu quero domá-lo...Mas a palavra captada no escuro, o som do violino captado no escuro, tem a mesma sensação, a mesma de olhá-lo, e o que segue um olhar no passado, emergido. (ANTONIO, 2006, 133)

Podemos postular que o romance Exumos é uma fabulação de um processo interior de revisão da escrita. Por isso tantas vezes o Eu fala de pedras e objetos fixos como pontos que se repetem ou ainda semelhantes a hifens que separam palavras e coisas. Este processo de revisão, 
sem dúvida, é bastante enérgico e dinâmico justamente por ser um ato angustiante. Mas a angústia de um livro assim é explicada por Bachelard assim:

Um livro angustiante oferece aos angustiados uma homeopatia da angústia. Mas essa homeopatia age sobretudo numa leitura meditada, na leitura valorizada pelo interesse literário. Então dois planos do psiquismo se cindem, o leitor participa desses dois planos e, quando se torna bastante consciente da estética da angústia, está bem perto de descobrir-lhe a facticidade. Porque a angústia é factícia: somos feitos para respirar livremente. (BACHELARD, 2009, p. 25).

Apesar dessa homeopatia da angústia, é com alegria que se respira a liberdade poética desses autores.

\section{CONSIDERAÇÕES FINAIS}

Portanto, o eu lírico parte da imagem/palavra e retorna a ela, expressando sua ânsia de sofrimento por meio da carga de apelo dramático, linguagem bastante explorada pelo artista, por exemplo, em suas peças teatrais. Esse diálogo desemboca em um projeto literário e epistemológico interdisciplinar onde se estabelecem diversas disciplinas subordinadas a uma instância maior chamada de metadisciplina que é uma metalinguagem. Uma espécie de registro de um método que se impõe como transdisciplinar, ou seja, que retira os saberes de suas "gavetas" empoeiradas. Trata-se de uma nova dialética a qual Bachelard prefere chamar de Ultraracionalismo. Ora, como aplicar esta dialética de sonhador a um antisistema? A poética dos espaços ancestrais nasce enquanto proposta para uma virada sintática na linguagem. Entretanto é uma 'coisa' a ser desenvolvida. Aqui neste texto expusemos brevemente nossas intenções a serem seguidas posteriormente em futuras publicações.

\section{REFERÊNCIAS BIBLIOGRÁFICAS}

ANTONIO, Fausto. Vinte anos de prosa. Editora Arte Literária. 2006.

BASTOS, Maria Beatriz. Literatura e Afrodescendência no Brasil: Antologia crítica. Editora UFMG. 2011.

BACHELARD, Gaston. A Poética do Devaneio. Editora Martins Fontes. São Paulo.2009. 
O Direito de sonhar. Editora BERTRAND BRASIL. Rio de Janeiro.1994.

A Psicanálise do Fogo. Editora Martins Fontes. São Paulo.2011.

CHEVALIER, Jean. Dicionário de Símbolos: mitos, sonhos, costumes, gestos,

formas, figuras, cores, números. 16ª edição. Rio de Janeiro: José Olympio, 2001.

COELHO, Nelly Novaes. Escritores brasileiros do século XX: Um testamento Crítico.

Editora Letra Selvagem. 2013.

FARACO, Carlos Alberto. Linguagem \& Diálogo. As ideias linguísticas do círculo de Bakhtin. Editora Parábola. 2010.

LUZ, Marco Aurélio. Agadá: dinâmica da civilização africanobrasileira. Salvador: Ed. Universidade da Bahia, 1995.

OLIVEIRA, Eduardo David de. Filosofia da Ancestralidade: Corpo e Mito na

Filosofia da Educação Brasileira. Curitiba: Editora gráfica Popular, 2007a.

Ancestralidade na Encruzilhada. Curitiba: Editora Gráfica Popular, 2007b.

Epistemologia da Ancestralidade. Disponível em:

www.entrelugares.ufc.br/entrelugares2/pdf/eduardo.pdf. Acesso em: 22/09/2011.

Cosmovisão Africana no Brasil: elementos para uma filosofia afrodescendente.

Curitiba: Editora Gráfica Popular, 2006. 